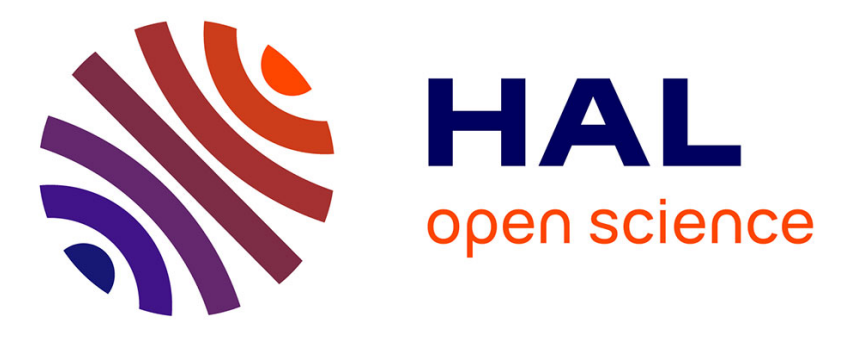

\title{
Ecological Modeling for the Extrapolation of Ecotoxicological Effects Measured during in Situ Assays in Gammarus
}

\author{
R. Coulaud, Olivier Geffard, A Coquillat, H. Quéau, Sandrine Charles, \\ Arnaud Chaumot
}

\section{- To cite this version:}

R. Coulaud, Olivier Geffard, A Coquillat, H. Quéau, Sandrine Charles, et al.. Ecological Modeling for the Extrapolation of Ecotoxicological Effects Measured during in Situ Assays in Gammarus. Environmental Science and Technology, 2014, 48 (11), pp.6428-6436. 10.1021/es501126g . hal-01191544

\section{HAL Id: hal-01191544 \\ https://hal.science/hal-01191544}

Submitted on 2 Sep 2015

HAL is a multi-disciplinary open access archive for the deposit and dissemination of scientific research documents, whether they are published or not. The documents may come from teaching and research institutions in France or abroad, or from public or private research centers.
L'archive ouverte pluridisciplinaire HAL, est destinée au dépôt et à la diffusion de documents scientifiques de niveau recherche, publiés ou non, émanant des établissements d'enseignement et de recherche français ou étrangers, des laboratoires publics ou privés. 


\section{Ecological modelling for the extrapolation of} Biométrie et Biologie Evolutive, F-69622 Villeurbanne, France. 


\section{KEYWORDS}

14 Gammarus fossarum, life-history, biomonitoring, population models, effect upscaling 


\section{ABSTRACT}

Evaluating the effects of chemical contamination on populations and ecological communities still constitutes a challenging necessity in environmental management. However the toxic effects of contaminants are commonly measured by means of organism-level responses. Linking such effects measures with ecological models is a promising way to apprehend population-level impacts. In this way, population models are currently increasingly used in predictive risk assessment procedures, but their use in environmental diagnostic

23 framework remains limited due to their lack of ecological realism. The present study with the crustacean Gammarus fossarum, a sentinel species in freshwater monitoring, combines a dual field and laboratory experimental approach with a population modelling framework. In this way, we developed an ecologically-relevant periodic matrix population model for Gammarus. This model allowed us to capture the population dynamics in the field, and to understand the particular pattern of demographic sensitivities induced by Gammarus life-history phenology. The model we developed provided a robust population-level assessment of in situ-based effects measures recorded during a biomonitoring program on a French watershed impacted by past mining activities. Thus, our study illustrates the potential of population modelling when seeking to decipher the role of environmental toxic contamination in ecological perturbations. 
TOC/Abstract graphic

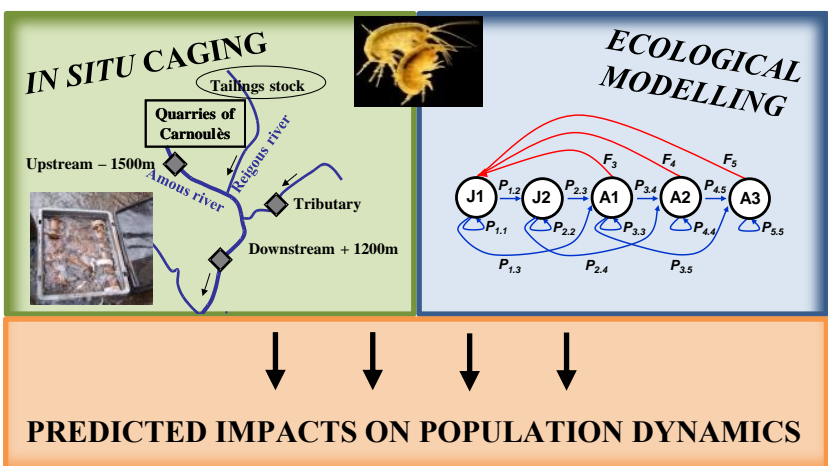




\section{INTRODUCTION}

In order to understand the role of chemical contamination in the degradation of environmental quality, the ecotoxicological approach studies the sub-lethal effects of contaminants by means of sub-individual biomarkers or individual responses. One can thus focus the diagnostic assessment at lower levels of biological organization compared to integrated ecological impact studies on populations, communities and ecosystem functioning 1-4. These organism-level markers are expected to be specific and sensitive to the toxic effects of contaminants. They are therefore used to gain insights into causal relationships between contamination and biological impacts, an essential step in proposing relevant environmental management programs. Nevertheless, their ecological relevance continues to be debated ${ }^{5}$. In fact, the effects detected by biomarkers and individual responses can be directly related to the presence of contaminants but do not inform on the severity of environmental quality degradation in terms of ecological effects, because they cannot be directly interpreted as predictors of the impacts on populations or communities, which constitute the protection goals of ecosystem management. One promising way to overcome this difficulty is to include the impacts measured on individual demographic parameters (e.g. survival, growth, reproduction) in population models to investigate adverse outcomes at the population level ${ }^{6-8}$. Nevertheless, although such population models are currently increasingly used in predictive approaches ${ }^{9}$, their use in the diagnostic framework remains limited. In the majority of studies, population models are based on laboratory data with species that are not representative of ecosystems. Consequently, while these models are useful for extrapolating the effects of a specific toxicant observed during a laboratory experiment on a model species to outcomes on the population growth rate for instance ${ }^{7,10}$, the integration of field-based input data in modelling approaches is lacking to really anticipate what would happen in the 
67 field in native populations ${ }^{11,12}$. Therefore, to develop the use of population models as

68 predictive tools, we need to develop models based on field data and autochthonous species.

69 In the present study, we aimed to develop an ecologically relevant population model for the crustacean Gammarus fossarum. Gammarids are recognized as tractable organisms for water quality biomonitoring ${ }^{6,13}$. We have recently contributed to the development of several subindividual biomarkers ${ }^{14-17}$ and individual markers ${ }^{4,18}$ for this sentinel species. Gammarids are considered as very promising species for multi-level assessment schemes from subindividual to population or community levels ${ }^{6}$. Here, in a first step, we report the implementation of a population modelling approach suited for the life-history and phenology of this invertebrate species. We parameterized a periodic matrix population model $12,19,20$ based on a 1-year study of a perennial population of $G$. fossarum. We used a combination of laboratory and in situ experiments in order to precisely characterize life-history trait dynamics throughout the year. This model allowed us to capture the population dynamics and to understand the particular pattern of demographic sensitivities in Gammarus, e.g. the relative importance of recruitment processes (fertility) vs survival processes, or the temporal variability of population vulnerability. In a second step, we demonstrate the suitability of this population model for a multi-level assessment of water quality based on a case study on the Amous watershed, a French river known to be contaminated by heavy metals due to mine drainage. Finally, we discuss the potential contribution of this type of population modelling approach to environmental monitoring, considering that biomarkers and individual responses could be complemented by population models to decipher the role of environmental contamination toxicity in ecological perturbations.

\section{MATERIALS AND METHODS}


We conducted our experiments on a long-established population of Gammarus fossarum which is present all the year upstream of the Ardières River $\left(04^{\circ} 31^{\prime} 16 \mathrm{E} ; 46^{\circ} 11^{\prime} 12 \mathrm{~N}\right.$, Rhône,

France). We used a dual approach combining laboratory and field experiments to characterize life-history trait variability throughout the year and population dynamics. On the one hand, used the length of the second segment of the antenna, which proved to be a robust indicator of 114 the body size in juveniles, adult males and females (data not shown). Concerning adults, we counted gammarids within the different substrates and separated in vivo gravid females. Then we conducted a field-based demographic sampling based on a monthly population census to estimate population characteristics (e.g. changes in density and size structure, fertility). On the other hand, we quantified the influence of water temperature throughout the year on the growth rate and interlaying interval, by coupling laboratory experiments and in situ validation. For all experiments, water temperature was recorded every $2 \mathrm{~h}$ using the Tinytag temperature logger Aquatic $2 ®$.

\section{Field-based demographic sampling}

A demographic sampling was conducted from November 2008 to November 2009. Each month, gammarids were sampled along a 50 -m river section using a hand net $(25 \times 18 \mathrm{~cm})$. Separate samples were taken for each substrate in the river, including favourable substrates for gammarids (i.e. bryophytes, leaves) and dominant substrates in the river (i.e. gravels). The percentage of each substratum was estimated on six transects shared out along the station. Samples were sieved on site at $1.25 \mathrm{~mm}$ to separate juveniles from adults. Juveniles were fixed in alcohol and adults were placed in buckets with river water. Juvenile densities were estimated within the different substrates with a sub-sample corresponding to $20 \%$ of the total sample from which we measured the body size of 60 individuals. For this measurement, we the body size of 60 individuals from the sample of gravid females was measured, and 60 
117 individuals from the sample of males and non-gravid females were sexed using a binocular

118 microscope and measured. This methodology allowed us to estimate monthly population

119 density, size distribution, sex ratio and percentage of gravid females. By this means, we also

120 determined size at birth, size at maturity and maximum size. In addition, every month we

121 measured size and fertility (number of embryos in the marsupium) on 60 gravid females

122 covering a wide range of sizes sampled randomly in the river section. The detailed fertility

123 measurement procedure is described in Geffard et al. ${ }^{18}$.

Quantification of the monthly variability in growth rates and interlaying intervals

Water temperature is known to influence the life-history traits of gammarids ${ }^{21-25}$.

Therefore, we expected that the variability in growth rates and interlaying intervals would be

mainly explained by water temperature variability during the year. Consequently, in the first step we studied the influence of water temperature on growth and interlaying interval under laboratory conditions. In the second step, we confirmed predictions using in situ caging assays.

132 Laboratory experiments. To estimate the influence of temperature on growth, we tested

133 three temperatures, $7.0( \pm 0.05), 12.1( \pm 0.01)$ and $16.4( \pm 0.03){ }^{\circ} \mathrm{C}$, as representative of the

134 range observed at the study site (mean monthly water temperature varied from 5.2 to $15.9^{\circ} \mathrm{C}$

135 in the year of the study). Because the growth was slow (in particular for low water 136 temperatures), we decided not to investigate growth from neonates to adults but to observe the 137 growth of three size classes of organisms simultaneously: $2.5( \pm 0.3) \mathrm{mm}, 4.5( \pm 0.8) \mathrm{mm}$ and $1385.8( \pm 0.7) \mathrm{mm}$. It allowed us to estimate growth from juveniles to adults using relatively 139 short experiments which is an advantage when studying gammarids under laboratory (e.g. no 140 nutrient deficiencies, less mortality). Gammarids were exposed to the three temperatures for 14156 days. We used four replicates of 15 individuals for the first size class and four replicates of 
14210 individuals for the other two. Gammarids were placed in 0.5 -L beakers filled with

143 continuously renewed water (four renewals per day; hardness $88 \mathrm{mg} \mathrm{L}^{-1}$ of $\mathrm{CaCO}_{3}$

144 corresponding to the hardness of the river at the study site). A pumping system maintained

145 oxygen in the beakers and a $16 \mathrm{~h} / 8 \mathrm{~h}$ light / dark photoperiod was applied. The organisms

146 were fed ad libitum with alder leaves conditioned in groundwater. Twice a week, freeze-dried

147 worms (Tubifex) were added. For the first size class, we also added frozen faeces from adult

148 batches. The body size of individuals was measured at days $0,14,32,46$ and 56 . After having

149 tested different classes of non-linear growth models, we chose to fit experimental data with a

150 logistic model. For each temperature, a logistic model was thus fit simultaneously considering

151 the three classes of gammarids. The model is expressed as follows:

$$
L(t)=\frac{\operatorname{Lmax}}{1+\left(\frac{\text { Lmax }}{\text { Linit }}-1\right) e^{(-r t)}}
$$

153 where $L(t)$ corresponds to the size of gammarids at time $t$ (in days), Lmax to the

maximum size, Linit to the size at the beginning of the experiment and $r$ to the daily growth

based demographic sampling (see below), we set $\operatorname{Lmax}$ at $8.5 \mathrm{~mm}$. For the quantification of

157 interlaying intervals, because laying is synchronous with moult in gammarids ${ }^{16,18,26}$, we used

158 the relationship established in a study on moulting dynamics (unpublished data). From this,

159 the influence of temperature $\theta$ (in ${ }^{\circ} \mathrm{C}$ ) on the interlaying interval $d$ (in days) is described by:

$$
d=\frac{(30.61-0.39 \theta)}{(0.01+0.05 \theta)}
$$

161 This hyperbolic relationship is consistent with studies reported for Gammarus $^{22,27 .}$

162 In situ assays. We tested the predictive ability of these models of temperature influence on 163 growth rates and interlaying intervals during four campaigns of in situ caging experiments at 
2008 for winter caging; April 2009 for spring; June 2009 for summer and October 2009 for

166 autumn). Mean water temperature during in situ experiments was ranged from 7.8 to $15.1^{\circ} \mathrm{C}$.

167 The gammarids were sampled and calibrated (i.e. selection of homogenous size) directly at

168 the study site. To determine growth rates, depending on the availability of gammarids, we

169 used from one to three size classes. For each size class, three replicates of 12 organisms were

170 placed in cylinders capped at their ends with pieces of netting (mesh size, $350 \mu \mathrm{m}$ ). Alder

171 leaves were supplied ad libitum. Initial sizes were estimated with a sample of 30 organisms.

172 After one month of exposure, gammarids were counted for survival estimation, placed in

173 alcohol and measured. Concerning the interlaying interval, we adapted the protocol proposed

174 in Geffard et al. ${ }^{18}$. Three replicates of seven pre-copulatory pairs of gammarids (i.e. male and

175 female on amplexus, with the female at the end of its reproductive cycle) were placed in

176 cylinders (diameter, $5 \mathrm{~cm}$; length, $10 \mathrm{~cm}$ ) capped at their ends with pieces of netting (mesh

177 size, $1 \mathrm{~mm}$ ). Alder leaves were supplied ad libitum. Every 2 days, gammarids were checked

178 in order to record the dates of moults (i.e. a first moult which occurred a few days after the

179 beginning of the experiment and a second which depended on temperature (between 4 and 8

180 weeks).

181

182 Modelling framework and demographic analysis

183 Development of the population model

184 We used a periodic Lefkovitch matrix population model with five size classes 19, 20, 28, 29

185 with the same structure as the model we previously developed for the gastropod

186 Potamopyrgus ${ }^{12}$. We employed a size-class rather than an age-class or a stage-class model

187 because (i) a strong correlation exists between body size and life-history traits in gammarids

$188^{22,25,27}$ and (ii) the life-history of individuals of such birth flow populations from short-living

189 species inhabiting variable environments (seasonality) strongly depends on their date of birth 
190 in the year, which makes age a very weak predictor of biological features. The present model

191 only deals with females and distinguishes two classes of juveniles - J1 (individuals with a

192 size up to $3.5 \mathrm{~mm}$ ) and $\mathrm{J} 2$ (size from $3.5 \mathrm{~mm}$ to the size at maturity) - and three classes of

193 adults - A1 (from the size at maturity to $6 \mathrm{~mm}$ ), A2 (from 6 to $7 \mathrm{~mm}$ ) and A3 (greater than 7

$194 \mathrm{~mm}$ ). This model can therefore integrate heterogeneity of demographic rates (survival, growth

195 and fertility) between size classes throughout the year.

196 Let $n_{i}(k)$ be the number of individuals of size class $i$ ( $i=1$ for $\mathrm{J} 1, i=2$ for $\mathrm{J} 2, i=3$ for A1, $i$

$197=4$ for A2 and $i=5$ for A3) at the beginning of month $k$. The five $n_{i}(k)$ variables can be

198 gathered in a population vector $\mathbf{n}(k)$. Then we can define 12 monthly matrices $\mathbf{M}_{k}$, which link

199 the population vectors $\mathbf{n}(k)$ between months $k$ and $k+1$ as follows:

200

$$
\mathbf{n}(k+1)=\mathbf{M}_{k} \mathbf{n}(k)
$$

201 with:

$$
\mathbf{M}_{k}=\left[\begin{array}{ccccc}
s_{1}(k)\left(1-\sum_{j>1} g_{1, j}(k)\right) & 0 & f_{3}(k) \sqrt{s_{1}(k)} \sqrt{s_{3}(k)} & f_{4}(k) \sqrt{s_{1}(k)} \sqrt{s_{4}(k)} & f_{3}(k) \sqrt{s_{1}(k)} \sqrt{s_{5}(k)} \\
s_{1}(k) g_{1,2}(k) & s_{2}(k)\left(1-\sum_{j>2} g_{2, j}(k)\right) & 0 & 0 & 0 \\
s_{1}(k) g_{1,3}(k) & s_{2}(k) g_{2,3}(k) & s_{3}(k)\left(1-\sum_{j>3} g_{3, j}(k)\right) & 0 & 0 \\
s_{1}(k) g_{1,4}(k) & s_{2}(k) g_{2,4}(k) & s_{3}(k) g_{3,4}(k) & s_{4}(k)\left(1-g_{4,5}(k)\right) & 0 \\
s_{1}(k) g_{1,5}(k) & s_{2}(k) g_{2,5}(k) & s_{3}(k) g_{3,5}(k) & s_{4}(k) g_{4,5}(k) & s_{5}(k)
\end{array}\right]
$$

where $s_{i}(k)$ is the survival rate (proportion) of the size class $i$ during month $k, g_{i, j}(k)$ the reproductive rate (mean number of juveniles produced per individual) of the size class $i$

$$
\mathbf{n}(t+1)=\left(\prod_{k=1}^{12} \mathbf{M}_{k}\right) \mathbf{n}(t)=\mathbf{L} \mathbf{n}(t)
$$




\section{Parameter estimation}

212 This matrix model encompasses three types of elements corresponding to survival, 213 reproductive and transition rates (see Coulaud et al. ${ }^{12}$ ). For each month $k$, we estimated the 214 parameters from our laboratory and field experiments. We estimated the reproductive rates $215 f_{i}(k)$ of the three adult classes $(i=3,4$ or 5$)$ as follows:

$$
f_{i}(k)=\frac{s r_{i}(k) b_{i}(k) \rho_{i}(k) \Delta t(k)}{d(k)}
$$

where $s r_{i}(k)$ (proportion of females) corresponds to the sex ratio of class $i$ during month $k$, the number of days of month $k$ and $d_{i}(k)$ to the interlaying interval in days computed for month $k$. Parameters $s r_{i}(k)$ and $\rho_{i}(k)$ were obtained with data from the demographic sampling (see above); parameters $b_{i}(k)$ were estimated for each size class from the relationship between body size $(\mathrm{mm})$ and fertility (number of embryos) obtained from the demographic sampling and parameters $d(k)$ were calculated according to eq. 2 with the mean

225 monthly water temperatures $\left({ }^{\circ} \mathrm{C}\right)$.We calculated transition rates $g_{i, j}(k)$ (proportion of 226 individuals from size class $i$ reaching a size embedded in class $j$ ) using the relationship 227 between growth rate $\left(\right.$ day $\left.^{-1}\right)$ and water temperature $\left({ }^{\circ} \mathrm{C}\right)$ (eq. 1) established during the 228 laboratory experiment and validated during in situ caging experiment (see above). Lastly, we estimated survival rates $s_{i}(k)$ for month $k$ from the comparison of densities (gammarid.m ${ }^{-2}$ )

230 observed during the demographic sampling (see above) in month $k$ with densities expected 231 from the observed densities in month $k-1$ combined with growth and reproductive rates estimated for month $k-1$. 
Model outcomes and elasticity analysis

235 The first dominant eigenvalue of the Lefkovitch matrix $\mathbf{L}, \lambda$, corresponds to the asymptotic 236 growth rate of the gammarid population ${ }^{28}$. The right eigenvector $w$ associated with this first 237 eigenvalue gives the asymptotic stable size structure. According to the matrix used first in the 238 product of the 12 monthly matrices $\mathbf{M}_{k}$, we obtained the size structure at the end of each 239 month of the year. Elasticities were calculated through the reduction in the asymptotic 240 population growth rate $\lambda$ induced by $10 \%$ reduction on all monthly matrices $\mathbf{M}_{k}$ in each life241 history trait successively and independently (i.e. survival of each class, fertility, reproductive 242 cycle duration and growth) before the calculation of the matrix L. We also examined the 243 monthly variability of this elasticity pattern. For this, we applied an episodic but more severe $24450 \%$ reduction in juvenile survival (s1 and s2), adult survival (s3, s4 and s5) and fertility 245 successively and independently on only one monthly matrix $\mathbf{M}_{k}$ before the calculation of the 246 matrix L.

\section{Case study on the Amous watershed}

249 Following the transplantation methodology developed in our group ${ }^{14-17}$, a campaign of in 250 situ assays was conducted in March 2008 in four stations of the Amous watershed, a French 251 river known to be contaminated by heavy metals originating from mine drainage from the 252 former mine at Carnoulès ${ }^{4,30}$. The same four stations as in these two previous studies were 253 considered: three stations along the Amous River: Upstream $-1500 \mathrm{~m}$, Downstream $+1200 \mathrm{~m}$ 254 and Downstream $+3500 m$ with different levels of metallic contamination (i.e., Upstream $-1500 m<$ Downstream $+3500 m<$ Downstream $+1200 m$, for metal bioaccumulation data not impacted by metal-loaded mine leachates. Juvenile survival, adult survival and fertility 
were measured in the different stations. We used gammarids from a station displaying good

water quality and currently used by our laboratory for in situ assays ${ }^{14-17}$ located upstream of the Bourbre River. To estimate juvenile survival, four replicates of 12 individuals were placed in cylinders capped at their ends with pieces of netting (mesh size, $350 \mu \mathrm{m}$ ). For adult survival and fertility, three replicates of seven pre-copulatory pairs were placed in cylinders (mesh size, $1 \mathrm{~mm}$ ). Gammarids were exposed for 21 days and were fed ad libitum with alder leaves. At the end of exposure, gammarids were counted and fertility was measured (i.e. number of embryos in the marsupium). To estimate population impacts, we integrated these different individual impacts into our population model in terms of percentage of demographic rate reduction in comparison to the control levels observed in the reference station Tributary.

\section{Statistical analyses}

270 Statistical procedures and population models were implemented with the R software ${ }^{31}$. 271 Before performing the ANOVA procedure, normality and homoscedasticity were checked 272 using the Shapiro-Wilk and Bartlett tests.

\section{RESULTS}

Field-based demographic sampling: size structure and fertility

276 Changes of size distribution in the population, as estimated with the monthly field-based

277 demographic sampling, are presented in Figure S1. The highest densities were observed in 278 autumn and at the beginning of winter, while the lowest densities were observed in winter and 279 spring. We observed highly fluctuating densities of juveniles, with very low densities in 280 spring and high densities during the rest of the year, particularly autumn. Contrasting with 281 juveniles, adults are present throughout the year with little variability and persist during 282 winter. Considering $1 \%$ and $99 \%$ percentiles in total size distributions, we estimated a size at 
birth equal to $2.3( \pm 0.2) \mathrm{mm}$ and a maximum size equal to $8.2( \pm 0.3) \mathrm{mm}$. Considering $1 \%$

284 percentiles of reproductive female size distributions, we estimated a size at maturity equal to

values (from 0.1 to $95 \%$ ). For all months, we observed an increase in this percentage between

the three size classes. Furthermore, we noted low percentages of reproductive females at the end of autumn and during winter, as well as high percentages during spring and summer. For

sex ratio $s r_{i}(k)$, we generally observed an equal number of males and females. Consequently, mean fertility of $3.6( \pm 1.3)$ embryos, A2 females a mean fertility of $5.1( \pm 1.6)$, and A3 females a mean fertility of $9.2( \pm 2.9)$ embryos.

\section{Monthly variability of growth rates and interlaying intervals}

The measurements taken during the laboratory experiment on growth are presented on

Figure S3 (A, B, C), showing that individuals grew faster when temperature increased. With

300 the logistic models fitted simultaneously on the three size classes (Figure S3 A, B, C), we estimated daily growth rates for each temperature. Between 7.0 and $16.4^{\circ} \mathrm{C}$, they varied from 0.008 to $0.021 \mathrm{day}^{-1}$. In this temperature range, consistent with temperatures recorded at the study site during the year, we fitted a linear model between water temperature $\theta$ (in ${ }^{\circ} \mathrm{C}$ ) and

304 daily growth rate $r\left(\right.$ day $\left.^{-1}\right)$ :

$$
r(\theta)=0.0014 \theta-0.0024
$$

306 During the in situ assays performed at different seasons, we observed substantial variability 307 in daily gain in size (i.e., between 0.011 and $0.052 \mathrm{~mm}$.day ${ }^{-1}$ depending on the season and the 
size-class). When the observed sizes were compared for each size class with values predicted

309 from the logistic model established in laboratory exposure (eq. 1) combined with (eq. 4), we

310 observed a good correlation (Spearman rank correlation test, $p<0.05, r^{2}=0.87$ ) (Figure S3

311 D), which validates the fact that this variability in growth rates is mainly related to water

312 temperature variability between the different caging experiments.

313 During the in situ experiments, we recorded an interlaying interval of 34 days in spring and

31426 days in summer. These values are consistent with model predictions from eq. 2, which

315 predicts durations of 35.5 and 27.1 days, respectively. During winter and autumn, we were

316 not able to follow females up to the end of the reproductive cycle due to the low temperature

317 which induces long reproductive cycles.

\section{Population model analysis}

320 Regarding parameter estimation (Table S1), we observed considerable monthly and between-class variability in reproductive rates $f_{i}(k)$, which varied from 0.01 to 7.07 in the mean number of juveniles produced per month per female. Concerning transition rates $g_{i, j}(k)$, we also observed high monthly variability, with a majority of individuals staying in their initial size class during the coldest months, whereas during months with a high water temperature, a majority of individuals moved up one or two size classes from month to month. Computed adult survival rates show substantial seasonal variability with low survival

327 rates in summer, whereas survival rates were high in winter and spring. Furthermore, size 328 class A3 showed the lowest survival rates for all months. Juvenile survival rates were 329 generally higher than adult survival rates. For some months, we calculated survival rates 330 higher than 1, in particular when densities were low (i.e. the uncertainty in count estimates 331 increased with smaller size samples) or for size class $\mathrm{J} 1$ (i.e. gammarids of the size class $\mathrm{J} 1$ 332 were very small and therefore difficult to sample, which makes density estimation difficult). 
333 To generate a more robust estimation of survival rates for each month $k$ to implement the

334 population model, we used the same smoothing methodology as in our study on the mollusc

335 Potamopyrgus ${ }^{12}$. We calculated the geometric mean of the survival rate estimates for months $336 k-1, k$ and $k+1$.

337 The asymptotic population growth rate $\lambda$ was estimated at 1.07. We computed the stable 338 size distribution corresponding to the structure of the population at the end of November, 339 February, May and August (Figure 1). We observed good consistency with field data of the 340 demographic sampling (chi-square tests not significant for the four seasons). The elasticity 341 analysis on matrix L (Figure 2) highlights that the asymptotic population growth rate $\lambda$ is 342 more sensitive to relative changes in juvenile survival rates than to changes in the other life343 history parameters. The life-history traits corresponding to the second highest elasticity are 344 the survival rates of small adults (i.e. elasticities of $s 3$ and $s 4$ ), followed by fertility $(b)$, 345 interlaying interval $(d)$, growth rate $(r)$ and survival rate of larger adults $(s 3)$. Although the 346 population is generally more sensitive to impacts on juvenile survival, when we applied 50\% 347 reductions in juvenile survival, adult survival or fertility rates successively on each monthly 348 matrix $\mathbf{M}_{k}$, we observed a strong variability of population sensitivity throughout the year 349 (Figure 3). Reduction in juvenile survival rates led to the highest impacts in June, then in 350 autumn. Concerning adult survival, we noted the highest impacts in winter with more than $35120 \%$ reduction in $\lambda$ when survival reduction occurred in January, February or March. Finally, 352 concerning fertility, we observed a bimodal pattern with the highest impacts in April and in 353 July-August.

\section{Case study on the Amous watershed}

356 In comparison to the reference station Tributary, we observed impacts on juvenile survival 357 rates $\left(s_{j}\right)$ in Upstream $-1500 m$ and Downstream $+1200 m$ (unilateral proportion test, $p<$ 
0.05 ), on adult survival rates $\left(s_{a}\right)$ in Downstream $+1200 m$ (unilateral proportion test, $p<$ 0.05 ) and on fertility $(b)$ in Upstream $-1500 m$ and Downstream $+3500 m$ (Wilcoxon rank sum test, $p<0.05$ ) (Table 1 A). In Downstream $+1200 m$, we did not record fertility due to excessively high adult mortality. When we applied simultaneously the effects in term of percentage of reduction in comparison to the reference site Tributary on all monthly matrices $\mathbf{M}_{k}$ before the calculation of the matrix $\mathrm{L}$, we predicted severe impacts on the asymptotic population growth rate in all contaminated stations (Table $1 \mathrm{~B}$, Table S2). We also calculated the specific impacts of the degradation of each life-history trait (Table $1 \mathrm{~B}$, Table S2) with a one-by-one application of the effects on each life-history-trait in term of percentage of reduction in comparison to the reference site Tributary. In this way, we noted that in Upstream $-1500 \mathrm{~m}$ impacts on fertility were responsible for the great majority of global impacts on population dynamics, whereas in Downstream $+1200 \mathrm{~m}$, reduction in juvenile survival rates had the greatest impact at the population level.

\section{DISCUSSION}

\section{Picturing the $G$. fossarum population biology in the field}

374 We have described the characteristics of one population of $G$. fossarum by means of a combination of a field survey and laboratory or in situ experiments. During the field-based 376 demographic sampling, we observed fluctuating densities throughout the year (Figure S1) 377 with high-density peaks (i.e. more than 800 gammarids per $\mathrm{m}^{2}$ in September and December) 378 and periods of lower densities, in particular at the end of winter and at the beginning of spring 379 . This high seasonal variability in gammarid density agrees with other studies on G. fossarum $380^{32-34}$. Our population is mainly composed of juveniles, except in spring where adults are more 381 abundant, agreeing with previous data ${ }^{32}$. In this way, the persistence of the population at the 382 beginning of spring when densities are minimal is ensured by the survival of an overwintering 
stock of adults. As for the percentage of reproductive females, we observed significant

384 between-month variability with a high percentage in summer and a very low percentage in winter. This pattern is consistent with other studies on G. fossarum ${ }^{32}$ or other gammarid species ${ }^{35,36}$, which report a higher reproductive activity in warm seasons. The estimation of 387 the seasonal variability of life-history traits confirmed our primary hypothesis that 388 temperature is the main source of variability. This is consistent with previous 389 ecophysiological studies, which have shown that daily growth rates $22,25,27,37$ and interlaying 390 intervals ${ }^{23,38-40}$ are mainly modulated by temperature. Density-dependent processes could 391 also be involved in temporal patterns of survival, and they could further be taken into account 392 with an appropriate amendment of our model. But we should dispose from a multi-year 393 demographic monitoring (ongoing study), to decipher whether such effects occur here in 394 Gammarus population dynamics.

395 Nevertheless, this complex population dynamics in a natural freshwater environment is well described by the different outcomes of our population model. Indeed, from the analysis of the 397 annual matrix model, a good match was found between the stable size distribution computed 398 for each season and the population structure observed during the field demographic sampling 399 (Figure 1). This highlights that the present modelling approach succeeds in properly describing the dynamics of this G. fossarum population throughout the year. It confirms that

401 periodic matrix population models with size classes can be very useful tools to capture the 402 dynamics of such small invertebrate species ${ }^{12}$. We showed that the population dynamics is 403 particularly vulnerable to juvenile mortality (Figure 2). This high sensitivity to juvenile 404 survival reduction is consistent with a study on the estuarine amphipod Leptocheirus 405 plumulosus ${ }^{41}$. More generally, it also agrees with Forbes et al. ${ }^{42}$, who concluded that benthic 406 macro-invertebrate species generally show a high sensitivity to reduction on juvenile survival 407 rates. 
In addition, the sensitivity of the Gammarus population studied varies substantially between months (Figure 3). For instance, the population dynamics appeared highly sensitive to adult survival reductions in winter, whereas it is more sensitive to fertility inhibitions in April, July and August. McGee and Spencer ${ }^{41,43}$ also concluded in high monthly variability of

412 population sensitivity, but the monthly sensitivity pattern was different in L. plumulosus.

413 These contrasting patterns highlight the role of species life-histories in governing 414 demographic impacts. The pattern of demographic sensitivity in G. fossarum is consistent 415 with our understanding of its population biology. We observed a functioning of the population 416 with two renewal time periods in the year. In spring, an overwintering stock of adults 417 provides the main contributors to population renewal, and this explains the high sensitivity to 418 the adult survival rate in winter and a peak of fertility sensitivity in April (Figure 3). The 419 juveniles produced by these surviving breeders in early spring reach maturity in summer and in turn contribute to the production of new individuals in the population. This results in a second peak of sensitivity to fertility inhibitions in July and August, preceded by a peak of 422 sensitivity to juvenile survival rate reductions in April and May. Thereafter, high sensitivity to 423 juvenile survival reduction appears during autumn, because the survivors from this second 424 wave of new individuals constitute the overwintering stock of adults, which mainly ensures 425 the population restarting in the next year. The modelling approach developed in this study is 426 thus suitable to mechanistically understand the complexity of the demographic processes 427 occurring in a wild G. fossarum population. Therefore, this approach can be used to anticipate 428 population impacts of life-history trait alterations caused by toxic environmental 429 contaminations, taking into account the influence of life-history and phenology for this effect upscalingat the population level. On a methodological point, our modelling approach would 
432 flow population, the analytical methodology of sensitivity analysis developed for periodic 433 matrix models ${ }^{20}$.

\section{Application to improve the ecological relevance of water quality diagnostic}

to perform an ecologically relevant assessment at the population level for diagnostic purposes

${ }^{6}$. On the one hand, the biomonitoring methodology of in situ caging makes it possible to measure the impact of toxicants on the life-history traits of native species in the field ${ }^{44}$. On

440 the other hand, population models, which are recognized as relevant tools for projecting 441 individual effects to consequences on population dynamics ${ }^{6-8}$, provide an assessment at an 442 ecologically relevant level of biological organization. We have illustrated this approach herein 443 with the Amous watershed study. At the three contaminated stations, we observed impacts on 444 life-history traits on caged gammarids (Table 1). When introducing these alterations of life445 history traits in the population model, in all cases we anticipated severe consequences on the 446 asymptotic population growth rate $\lambda$ (between 80 and $99 \%$ reduction, Table 1 ). Interestingly, 447 we also separately considered the potential reduction in $\lambda$ of the impacts observed on the 448 different life-history traits. Thereby, in comparison with the reference station Tributary, we 449 observed that a $15 \%$ reduction in the juvenile survival rate (i.e. in the station Upstream -1500 $m$ ) impacts $\lambda$ with the same severity as a $56 \%$ reduction in the adult survival rate (i.e. in the station Downstream $+1200 \mathrm{~m}$ ) or a $58 \%$ reduction in fertility (i.e. in the station Downstream $452+3500 \mathrm{~m}$ ). This pattern is explained by the greater sensitivity of population dynamics to 453 impacts on juvenile survival as revealed by the model's elasticity analysis. Of note, 454 accrediting the relevance of the model predictions, a natural gammarid population is present 455 all along the year in the station Tributary, while no gammarids can be harvested in the two 456 contaminated Downstream stations. In the station Upstream $-1500 \mathrm{~m}$, gammarids can be found 
episodically, but these are mainly adults, with high occurrence of necrotic gills; no embryos are present in females, and juvenile density is quite null. These observations indicate that organisms present in this station do not constitute a durable population, but are rather drifting animals from more upstream pristine areas.

Furthermore, this modelling approach with periodic matrix population models has particular value for the diagnostic of water quality. Indeed, in addition to characterizing the impact of toxicants in persistent chronic pollution contexts, the periodic structure of these models can anticipate the impact of pulsed sources of contamination, such as peaks of pesticides or contaminations with seasonal variability due to water flow, run-off or effluent emission management. This is in fact particularly relevant with regard to significant between-month differences in population vulnerability (Figure 3). Thus the development of population models that integrate seasonality is a relevant way to increase our ability to project toxic effects on individual performance onto population demographic consequences. One question still to be resolved is how much between-population and between-species variability of life-history phenology could condition the relevance of the approach, which presumed a genericity of demographic patterns in Gammarids.

Finally, this study contributes to establishing gammarids as sentinel species for European freshwater ecosystems ${ }^{6,13}$. Indeed, we have already mentioned that numerous biomarkers tracking toxic effects at the molecular level and in situ bioassay protocols are available in these species. Here we demonstrate how alterations of life-history traits could be translated in terms of potential population impacts, by means of an ecologically relevant population model. Therefore, gammarids are good candidates to elaborate multilevel assessment schemes for environmental monitoring. Indeed, based on mechanistic hypotheses as proposed for the predictive hazard assessment of chemical compounds ${ }^{45-47}$, one could establish quantitative links between sub-individual biomarker responses and individual performance alterations ${ }^{48-}$ 
$482^{50}$, and then use population modelling. In the context of environmental management, this 483 could allow combining the sensitivity and the specificity of field ecotoxicological tools with 484 the ecological relevance of a diagnostic of toxicity projected at the population level.

\section{ASSOCIATED CONTENT}

\section{Supporting Information}

Supporting information provides details on biological data measurement allowing the parameterization of the population model. Figure S1 relates monthly field-based demographic sampling data, Figure S2 relates details on the relationship between body size and female

491 fertility, and Figure S3 relates details on growth experiments. Table S1 gives the different parameters of the population model (reproductive rates, transition rates and survival rates) and Table S2 gives the actual lambda values corresponding to the Table $1 \mathrm{~B}$. This material is available free of charge via the Internet at http://pubs.acs.org.

\section{AUTHOR INFORMATION}

\section{Corresponding Author}

*Phone: 334 72208788. Fax: 334 78477875. E-mail: arnaud.chaumot@irstea.fr.

499 Corresponding author address: Irstea, UR MALY, 5 rue de la doua - CS70077, F-69626

500 Villeurbanne, France.

\section{$501 \quad$ Note}

502 The authors declare no competing financial interest. 

financial grants, and the ANR CESA program GAMMA 02102 "Variability-adaptationdiversity and Ecotoxicology in gammarids" (2012-2015).

\section{REFERENCES}

510 1. Chapman, P. M., Determining when contamination is pollution - Weight of evidence 511 determinations for sediments and effluents. Environ. Int. 2007, 33, (4), 492-501.

512 2. Dagnino, A.; Sforzini, S.; Dondero, F.; Fenoglio, S.; Bona, E.; Jensen, J.; Viarengo, 513 A., A "Weight-of-Evidence" approach for the integration of environmental "Triad" data to 514 assess ecological risk and biological vulnerability. Integr. Environ. Assess. Manage. 2008, 4, $515 \quad(3), 314-326$.

517 M. V. M.; Barata, C., Combined use of Daphnia magna in situ bioassays, biomarkers and 518 biological indices to diagnose and identify environmental pressures on invertebrate communities in two Mediterranean urbanized and industrialized rivers (NE Spain). Aquat. Toxicol. 2008, 87, (4), 310-320. influence of confounding factors to improve water quality biomonitoring. Water Res. 2011, 45, 6417-6429. 
6. Baird, D. J.; Brown, S. S.; Lagadic, L.; Liess, M.; Maltby, L.; Moreira-Santos, M.;

528 Schulz, R.; Scott, G. I., In situ-based effects measures: determining the ecological relevance of measured responses. Integr. Environ. Assess. Manage. 2007, 3, (2), 259-267.

7. Forbes, V. E.; Calow, P.; Grimm, V.; Hayashi, T. I.; Jager, T.; Katholm, A.; 531 Palmqvist, A.; Pastorok, R.; Salvito, D.; Sibly, R.; Spromberg, J.; Stark, J.; Stillman, R. A., 532 Adding value to ecological risk assessment with population modeling. Hum. Ecol. Risk 533 Assess. 2011, 17, (2), 287-299. 257. population models in the european ecological risk assessment of chemicals II: Review of models and their potential to address environmental protection aims. Integr. Environ. Assess. Manage. 2010, 6, (3), 338-360. toxicity data across two levels of biological organization. Environ. Toxicol. Chem. 2006, 25, (2), 589-596.

11. Hansen, F.; Forbes, V. E.; Forbes, T. L., Using elasticity analysis of demographic 545 models to link toxicant effects on individuals to the population level: an example. Funct. 546 Ecol. 1999, 13, (2), 157-162. mudsnail Potamopyrgus antipodarum. Environ. Toxicol. Chem. 2013, 32, (8), 1727-1736. 
13. Kunz, P. Y.; Kienle, C.; Gerhardt, A., Gammarus spp. in aquatic ecotoxicology and water quality assessment: Toward integrated multilevel tests. Rev. Environ. Cont. Toxicol. 2010, 205, 1-76.

14. Xuereb, B.; Chaumot, A.; Mons, R.; Garric, J.; Geffard, O., Acetylcholinesterase activity in Gammarus fossarum (Crustacea Amphipoda). Intrinsic variability, reference levels, and a reliable tool for field surveys. Aquat. Toxicol. 2009, 93, (4), 225-233.

15. Lacaze, E.; Geffard, O.; Bony, S.; Devaux, A., Genotoxicity assessment in the Toxicol. Environ. Mutag. 2010, 700, (1-2), 32-38.

562 of oocyte quality and endocrine disruption biomarker in males. Aquat. Toxicol. 2012, 112$113,72-82$.

17. Charron, L.; Geffard, O.; Chaumot, A.; Coulaud, R.; Queau, H.; Geffard, A.; Dedourge-Geffard, O., Effect of water quality and confounding factors on digestive enzyme activities in Gammarus fossarum. Environ. Sci. Pollut. Res. 2013, 1-13.

18. Geffard, O.; Xuereb, B.; Chaumot, A.; Geffard, A.; Biagianti, S.; Noël, C.; Abbaci,

568 K.; Garric, J.; Charmantier, G.; Charmantier-Daures, M., Ovarian cycle and embryonic 569 development in Gammarus fossarum: Application for reproductive toxicity assessment. 570 Environ. Toxicol. Chem. 2010, 29, (10), 2249-2259. 
573

574

575

576

577

578

579

580

581

582

583

584

585

586

587

588

589

20. Caswell, H.; Shyu, E., Sensitivity analysis of periodic matrix population models. Theor. Popul. Biol. 2012, 82, (4), 329-339.

21. Pöckl, M.; Webb, B. W.; Sutcliffe, D. W., Life history and reproductive capacity of Gammarus fossarum and G. roeseli (Crustacea: Amphipoda) under naturally fluctuating water temperatures: A simulation study. Freshwat. Biol. 2003, 48, (1), 53-66.

22. Pöckl, M., Effects of temperature, age and body size on moulting and growth in the freshwater amphipods Gammarus fossarum and G. roeseli. Freshwat. Biol. 1992, 27, (2), 211 225.

23. Pöckl, M.; Timischl, W., Comparative study of mathematical models for the relationship between water temperature and brood development time of Gammarus fossarum and G. roeseli (Crustacea: Amphipoda). Freshwat. Biol. 1990, 23, (3), 433-440.

24. Sutcliffe, D. W.; Carrick, T. R.; Willoughby, L. G., Effects of diet, body size, age and temperature on growth rates in the amphipod Gammarus pulex. Freshwat. Biol. 1981, 11, (2), 183-214.

25. Neuparth, T.; Costa, F. O.; Costa, M. H., Effects of temperature and salinity on life history of the marine amphipod Gammarus locusta. Implications for ecotoxicological testing. Ecotoxicology 2002, 11, (1), 61-73.

26. Hyne, R. V., Review of the reproductive biology of amphipods and their endocrine regulation: Identification of mechanistic pathways for reproductive toxicants. Environ. Toxicol. Chem. 2011, 30, (12), 2647-2657.

27. Pöckl, M., Laboratory studies on growth, feeding, moulting and mortality in the freshwater amphipods Gammarus fossarum and G. roeseli. Arch. Hydrobiol. 1995, 134, (2), 223-253. 
28. Caswell, H., Matrix Population Models. John Wiley \& Sons, Ltd: 2001.

29. Lefkovitch, L. P., The study of population growth in organisms grouped by stages.

598 Biometrics 1965, 21, 1-18.

599 30. Dedourge-Geffard, O.; Palais, F.; Biagianti-Risbourg, S.; Geffard, O.; Geffard, A., 600 Effects of metals on feeding rate and digestive enzymes in Gammarus fossarum: An in situ 601 experiment. Chemosphere 2009, 77, (11), 1569-1576.

602 31. R Development Core Team, $R:$ A Language and Environment for Statistical 603 Computing. R Foundation for Statistical Computing: 2013.

604 32. Ladewig, V.; Jungmann, D.; Köhler, H. R.; Schirling, M.; Triebskorn, R.; Nagel, R., 605 Population structure and dynamics of Gammarus fossarum (Amphipoda) upstream and 606 downstream from effluents of sewage treatment plants. Arch. Environ. Contam. Toxicol. 607 2006, 50, (3), 370-383.

608 33. Beracko, P.; Sýkorová, A.; Štangler, A., Life history, secondary production and 609 population dynamics of Gammarus fossarum (Koch, 1836) in a constant temperature stream. $610 \quad$ Biologia 2012, 67, (1), 164-171.

611 34. Welton, J. S., Life-history and production of the amphipod Gammarus pulex in a 612 Dorset chalk stream. Freshwat. Biol. 1979, 9, (3), 263-275.

613 35. Costa, F. O.; Costa, M. H., Life history of the amphipod Gammarus locusta in the 614 Sado estuary (Portugal). Acta Oecol. 1999, 20, (4), 305-314.

615 36. Sutcliffe, D. W., Reproduction in Gammarus (Crustacea, Amphipoda): female 616 strategies. Freshwat. Forum 1993, 3, (26-64). 
617 37. Duran, M., Estimating the growth rate of Gammarus pulex (L.) from the River

618 Yeşilirmak (Turkey). Arch. Hydrobiol. 2004, 161, (4), 553-559.

619 38. Pöckl, M., Reproductive potential and lifetime potential fecundity of the freshwater 620 amphipods Gammarus fossarum and G. roeseli in Austrian streams and rivers. Freshwat. Biol. 621 1993, 30, (1), 73-91.

39. Sutcliffe, D. W., Reproduction in Gammarus (Crustacea, Amphipoda): basic processes. Freshwat. Forum 1992, 2, (102-128).

40. Maranhão, P.; Marques, J. C., The influence of temperature and salinity on the duration of embryonic development, fecundity and growth of the amphipod Echinogammarus marinus Leach (Gammaridae). Acta Oecol. 2003, 24, (1), 5-13.

41. McGee, B. L.; Spencer, M., A field-based population model for the sediment toxicity test organism Leptocheirus plumulosus: II. Model application. Mar. Environ. Res. 2001, 51, (4), 347-363.

42. Forbes, V. E.; Calow, P.; Sibly, R. M., Are current species extrapolation models a good basis for ecological risk assessment? Environ. Toxicol. Chem. 2001, 20, (2), 442-447. test organism Leptocheirus plumulosus: I. Model development. Mar. Environ. Res. 2001, 51, (4), 327-345. 
45. Kramer, V. J.; Etterson, M. A.; Hecker, M.; Murphy, C. A.; Roesijadi, G.; Spade, D.

639 J.; Spromberg, J. A.; Wang, M.; Ankley, G. T., Adverse outcome pathways and ecological

640 risk assessment: Bridging to population-level effects. Environ. Toxicol. Chem. 2011, 30, (1), $641 \quad 64-76$.

642 46. Ankley, G. T.; Bennett, R. S.; Erickson, R. J.; Hoff, D. J.; Hornung, M. W.; Johnson, 643 R. D.; Mount, D. R.; Nichols, J. W.; Russom, C. L.; Schmieder, P. K.; Serrrano, J. A.; Tietge, 644 J. E.; Villeneuve, D. L., Adverse outcome pathways: A conceptual framework to support 645 ecotoxicology research and risk assessment. Environ. Toxicol. Chem. 2010, 29, (3), 730-741.

646 47. Miller, D. H.; Jensen, K. M.; Villeneuve, D. L.; Kahl, M. D.; Makynen, E. A.; Durhan, 647 E. J.; Ankley, G. T., Linkage of biochemical responses to population-level effects: A case 648 study with vitellogenin in the fathead minnow (Pimephales promelas). Environ. Toxicol. 649 Chem. 2007, 26, (3), 521-527.

650 48. Jager, T.; Hansen, B. H., Linking survival and biomarker responses over time. 651 Environ. Toxicol. Chem. 2013, 32, (8), 1842-1845.

652 49. Lacaze, E.; Geffard, O.; Goyet, D.; Bony, S.; Devaux, A., Linking genotoxic 653 responses in Gammarus fossarum germ cells with reproduction impairment, using the Comet 654 assay. Environ. Res. 2011, 111, (5), 626-634.

655 50. Xuereb, B.; Lefèvre, E.; Garric, J.; Geffard, O., Acetylcholinesterase activity in 656 Gammarus fossarum (Crustacea Amphipoda): Linking AChE inhibition and behavioural 657 alteration. Aquat. Toxicol. 2009, 94, (2), 114-122. 
660 Table 1. A) Juvenile survival (\%), adult survival (\%) and fertility (embryos per females)

661 values measured in the stations in the Amous watershed. * indicated significant inhibitions in 662 comparison with the reference station Tributary. B) Percentage of inhibition of population 663 growth rate $\lambda$ caused by the different individual impacts observed in the three contaminated 664 stations.

\section{Stations}

Tributary Upstream $-1500 m$ Downstream $+1200 m$ Downstream $+3500 m$

\section{A) Recorded individual traits during in situ assay}

\begin{tabular}{|c|cccc|}
\hline $\begin{array}{c}\text { juvenile survival } \\
(\%)\end{array}$ & 83 & $71^{*}$ & $19^{*}$ & 95 \\
$\begin{array}{c}\text { adult survival (\%) } \\
\text { fertility } \\
\text { (embryos per female) }\end{array}$ & 96 & 92 & $42^{*}$ & 94 \\
\hline $\begin{array}{l}\text { B) Projected population impacts } \\
\text { (\% reduction in the asymptotic population growth rate } \lambda)\end{array}$ & $1.7^{*}$ & $/$ & $7.5^{*}$ \\
\hline all traits & $/$ & 99 & & \\
juvenile survival & $/$ & 65 & 99 & no impact \\
adult survival & $/$ & no impact & 81 & no impact \\
fertility & $/$ & 98 & $/$ & 80 \\
\hline
\end{tabular}

665 

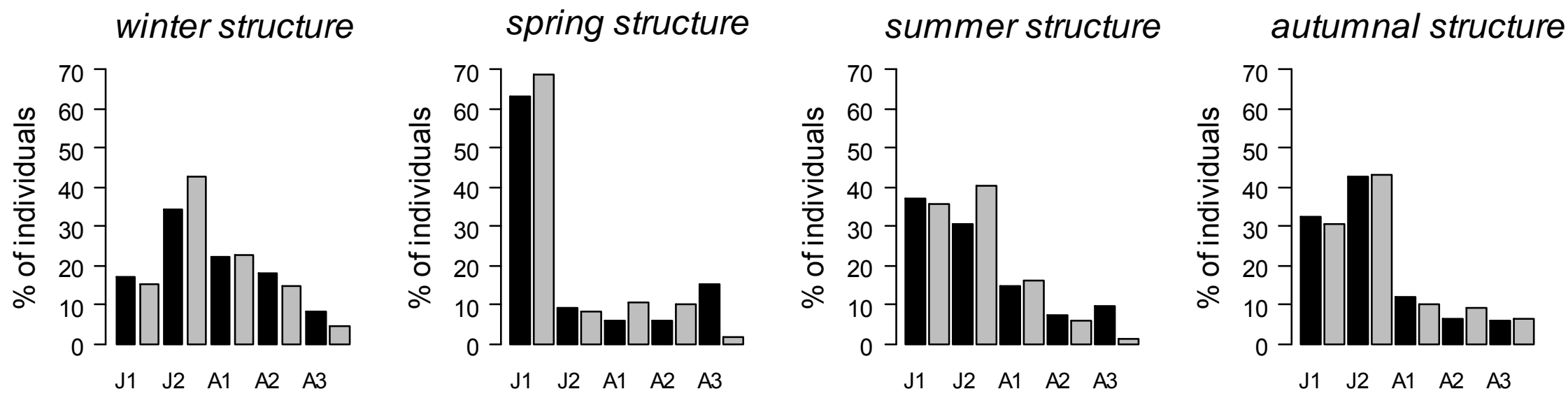

668

Figure 1. Stable size distributions computed from the population model (in black) and size-distributions observed during the field-based demographic sampling of the Gammarus fossarum population (in grey). J1 and J2 correspond to the two classes of juveniles of the model; A1, $\mathrm{A} 2$ and $\mathrm{A} 3$ correspond to the three classes of adults. 


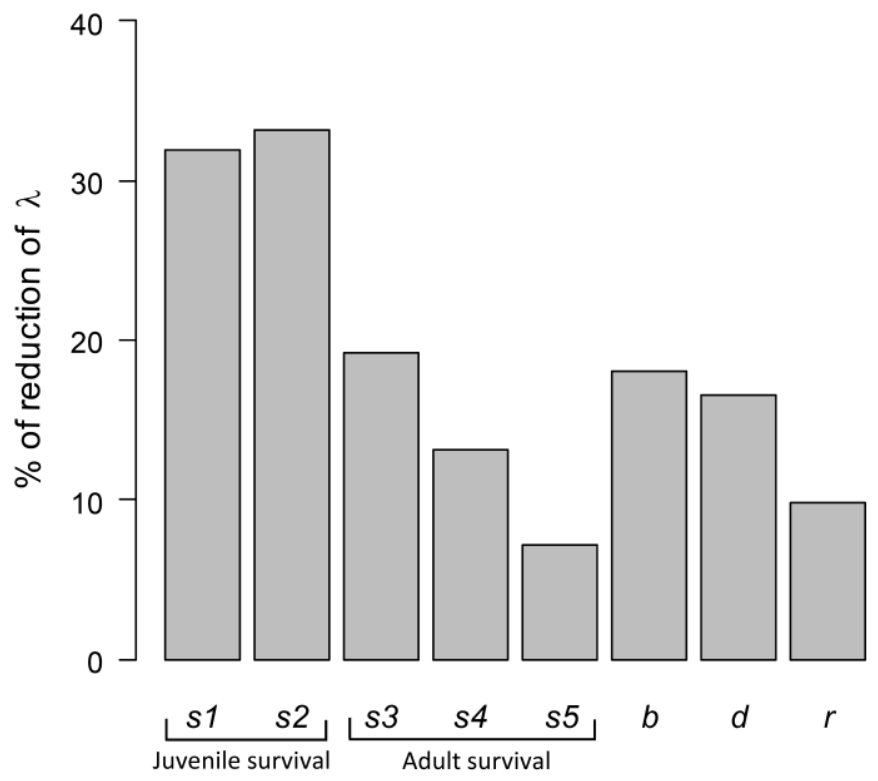

673 Figure 2. Reduction in the annual asymptotic population growth rate $\lambda$ induced by a $10 \%$

674 reduction in juvenile survival rates (s1 and s2), adult survival rates (s3, s4 and s5), fertility (b), 675 growth $(r)$ or a $10 \%$ increase in reproductive cycle duration $(d)$ applied simultaneously to each 676 month of the year. 


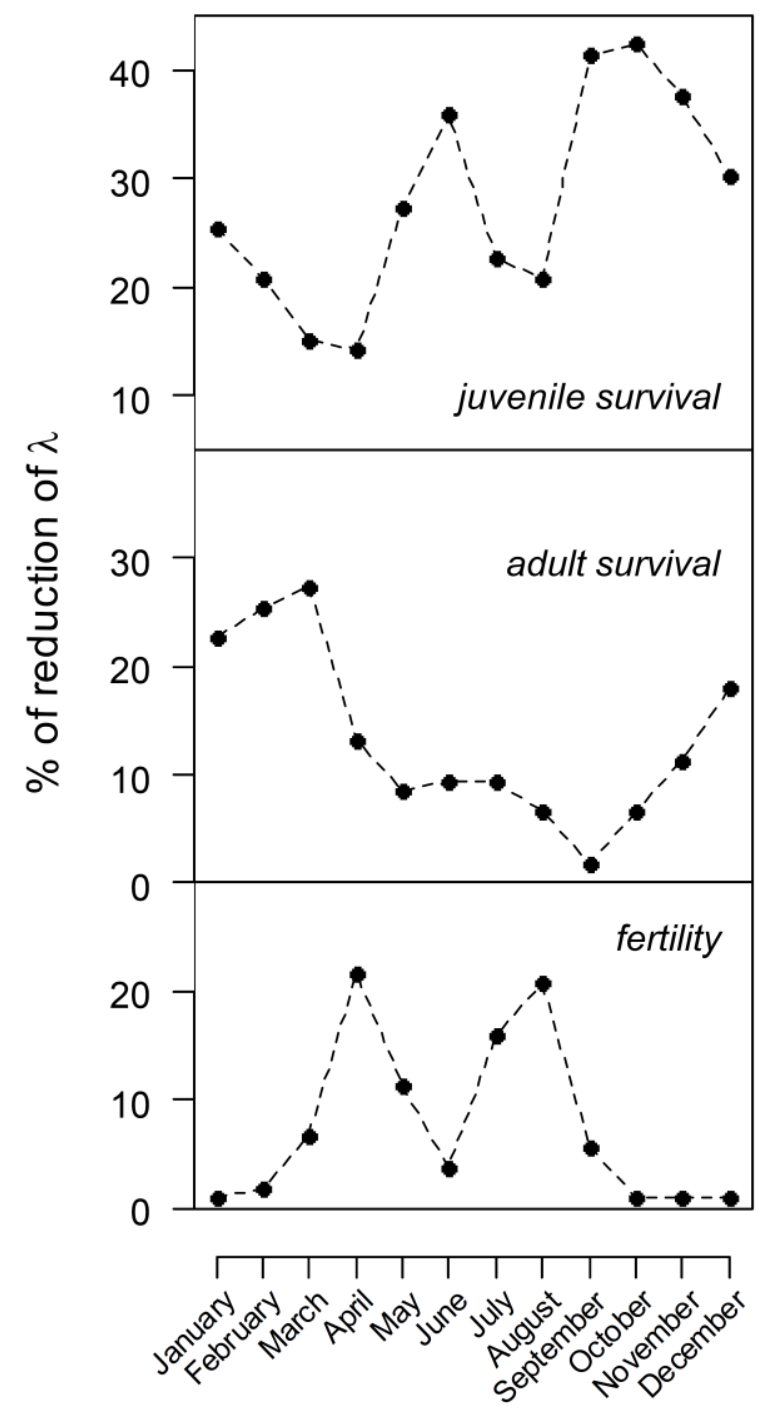

678 Figure 3. Reduction in annual asymptotic population growth rate $\lambda$ induced by a $50 \%$ reduction

679 in juvenile survival rates (s1 and s2), adult survival rates (s3, s4 and s5) and fertility applied 680 during the different months in the year. 